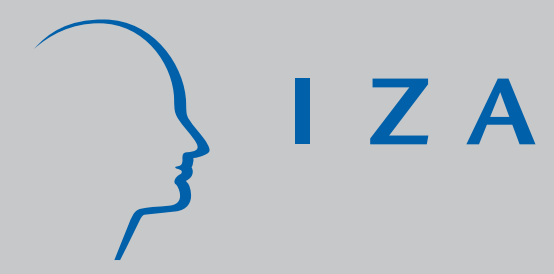

IZADP No. 4091

Economic Growth with Political Lobbying and Wage Bargaining

Tapio Palokangas

March 2009 


\title{
Economic Growth with Political Lobbying and Wage Bargaining
}

\author{
Tapio Palokangas \\ University of Helsinki, \\ HECER and IZA
}

Discussion Paper No. 4091

March 2009

\author{
IZA \\ P.O. Box 7240 \\ 53072 Bonn \\ Germany \\ Phone: +49-228-3894-0 \\ Fax: +49-228-3894-180 \\ E-mail: iza@iza.org
}

Any opinions expressed here are those of the author(s) and not those of IZA. Research published in this series may include views on policy, but the institute itself takes no institutional policy positions.

The Institute for the Study of Labor (IZA) in Bonn is a local and virtual international research center and a place of communication between science, politics and business. IZA is an independent nonprofit organization supported by Deutsche Post Foundation. The center is associated with the University of Bonn and offers a stimulating research environment through its international network, workshops and conferences, data service, project support, research visits and doctoral program. IZA engages in (i) original and internationally competitive research in all fields of labor economics, (ii) development of policy concepts, and (iii) dissemination of research results and concepts to the interested public.

IZA Discussion Papers often represent preliminary work and are circulated to encourage discussion. Citation of such a paper should account for its provisional character. A revised version may be available directly from the author. 


\begin{abstract}

\section{Economic Growth with Political Lobbying and Wage Bargaining*}

This paper examines an economy with a large number of industries, each producing a different good. Technological change follows a Poisson process where firms improve their productivity through investment in R\&D. The less there are firms in the economy or the more they can coordinate their actions, the higher their profits. Labor is used in production or R\&D. All workers are unionized and their wages depend on relative union bargaining power. If this power is high enough, then there is involuntary unemployment. Both workers and firms lobby the central planner of the economy which affects firms' and unions' market power. The main findings of the paper can be summarized the follows. The central planner can increase its welfare either (a) by increasing the level of income or (b) by speeding up economic growth. If (a) is more effective than (b), then the central planner eliminates union power altogether to have full employment. On the other hand, if (b) is more effective than (a), then the central planner supports labor unions to promote cost-escaping R\&D.
\end{abstract}

JEL Classification: F15, J50, O40

Keywords: economic integration, labor unions, market power, endogenous technological change

Corresponding author:

Tapio Palokangas

Department of Economics

P.O. Box 17 (Arkadiankatu 7)

FIN-00014 University of Helsinki

Finland

E-mail: Tapio.Palokangas@helsinki.fi

\footnotetext{
* Financial support from the Yrjö Jahnsson Foundation is gratefully acknowledged. I am also grateful to Arkady Kryazhimskiy for constructive comments.
} 


\section{Introduction}

I consider an economy with a fixed number $J$ of similar industries. ${ }^{1}$ Each industry possesses a fixed amount $L$ of labor, a representative firm and a representative labor union. To examine the political economy of growth and economic integration, the model is composed as follows:

(i) Firms produce one unit of output from one labor unit. The prices are determined by oligopolistic competition.

(ii) Workers and firms bargain over wages.

(iii) Firms invest in $R \& D$ to escape production costs.

(iv) The decision maker of the economy, called the central planner, has its own interests and regulates the product and labor markets. The interest groups that represent workers and firms lobby the central planner.

I summarize the institutional structure of the model as:

\begin{tabular}{l|ll} 
Agents & $\begin{array}{l}\text { Representatives } \\
\text { in wage bargaining }\end{array}$ & $\begin{array}{l}\text { Representatives } \\
\text { in lobbying the } \\
\text { central planner }\end{array}$ \\
\hline $\begin{array}{l}\text { Workers } \\
\text { Firms }\end{array}$ & $\begin{array}{l}\text { Labor unions } \\
\text { Employer federation }\end{array}$ & $\begin{array}{l}\text { Worker lobby } \\
\text { Employer lobby }\end{array}$ \\
\hline
\end{tabular}

I use the common agency model (e.g. Bernheim and Whinston (1986), Grossman and Helpman (1994a), and Dixit at al. (1997) to establish a political equilibrium with the following sequence of decisions:

1. Worker and employer lobbies make their offers to the central planner. These offers relate the lobbies' prospective political contributions to the central planner's policy.

2. The central planner regulates the product and labor markets. Product market regulation determines how much firms can coordinate their actions in price settlement, and labor market regulation determines the relative power of the labor unions in wage bargaining.

\footnotetext{
${ }^{1}$ The assumption on similar industries is admittedly strong, but with asymmetric industries there is no analytical result in the model.
} 
3. Unions and employers bargain over the wages.

4. Firms decide how much to invest in R\&D.

5. Each firm decides on its output given its expectations on the behavior of the other firms.

6. The households decide on their consumption.

This extended game is solved by backward induction.

\section{Production and consumption}

In industry $j \in\{1, \ldots, J\}$, a single firm (hereafter firm $j$ ) produces good $j$ from labor with technology

$$
y_{j}=B_{j} n_{j}
$$

where $y_{j}$ output, $n_{j}$ labor input in production and $B_{j}$ is the productivity parameter. I assume that all products $j \in\{1, \ldots, J\}$ are perfect substitutes, for simplicity. ${ }^{2}$

All households in the economy share the same preferences and take income, the prices and the interest rate $r$ as given. Thus, they all behave as if there were a single representative household which chooses its flow of consumption $C$ to maximize its utility starting at time $T$,

$$
\int_{T}^{\infty}(\log C) e^{-\rho(\theta-T)} d \theta
$$

where $\theta$ is time, $C$ consumption and $\rho>0$ the constant rate of time preference. The total supply of the composite good, $C$, is the sum of industrial outputs $y_{j}, C=\sum_{j=1}^{J} y_{j}$.Noting this, the maximization leads to the Euler equation [cf. Grossman and Helpman (1994b)]

$$
\dot{\mathcal{E}} / \mathcal{E}=r-\rho \quad \text { with } \quad \mathcal{E} \doteq p C=p \sum_{j=1}^{J} y_{j}
$$

where $p$ the consumption price, $\mathcal{E}$ total consumption expenditure, $r$ the interest rate and $\dot{\mathcal{E}}=d \mathcal{E} / d t$. Because in the model there is no money that would

\footnotetext{
${ }^{2}$ With some complication, it is possible to use a CES function here for the same purpose.
} 
pin down the nominal price level at any time, it is convenient to normalize total consumption expenditure $\mathcal{E}$ at the constant number $J$ of industries. This and (2) yield

$$
\mathcal{E}=p=\mathcal{E} / \sum_{j=1}^{J} y_{j}=J / \sum_{j=1}^{J} y_{j}, \quad r=\rho>0 .
$$

\section{Firms}

\subsection{Competition in the product market}

Following Dixit (1986), I assume that each firm $j$ anticipates the reaction of the other firms $k \neq j$ by

$$
d y_{k} / d y_{j}=\varphi y_{k} / y_{j} \text { for } k \neq j
$$

where $\varphi \in(0,1)$ is a measure of the firms' market power. If $\varphi=0$, the firms behave in Cournot manner, taking each others' output level as given. The higher $\varphi$, the more the firms can coordinate their actions and the higher price they can charge. The central planner can decrease (increase) $\varphi$ by intensifying (weakening) its competition and anti-trust policies. The product market is fully deregulated for $\varphi=0$.

I assume, for simplicity, uniform initial productivity in the economy, $B_{k}^{0}=$ $B^{0}$ for all $k$. This implies symmetry $y_{k}=y$ for all $k$. Noting (3) and (4), the inverse of the anticipated price elasticity of demand for firm $j$ is then

$$
\begin{aligned}
\phi(\varphi) & \doteq-\left[\frac{y_{j}}{p} \frac{d p}{d y_{j}}\right]_{y_{k}=y}=\left[\frac{y_{j}}{\sum_{k=1}^{J} y_{k}} \frac{d \sum_{k=1}^{J} y_{k}}{d y_{j}}\right]_{y_{k}=y}=\frac{1}{J}\left[\sum_{k=1}^{J} \frac{d y_{k}}{d y_{j}}\right]_{y_{k}=y} \\
& =\frac{1}{J}\left[1+\varphi \sum_{k \neq j} \frac{y_{k}}{y_{j}}\right]_{y_{k}=y}=(1-\varphi) / J+\varphi .
\end{aligned}
$$

By controlling $\varphi$, the central planner can determine $\phi$.

Firm $j$ maximizes its profit $\pi_{j} \doteq p y_{j}-w_{j} n_{j}$, where $y_{j}$ is output, by its labor input $n_{j}$ holding the wage $w_{j}$ and productivity $B_{j}$ constant, given the production function (1) and the price elasticity of the demand for output, (5). Noting (3), this maximization yields the conditions

$$
\begin{aligned}
& w_{j}=\left[p+y_{j} \frac{d p}{d y_{j}}\right] B_{j}=(1-\phi) p B_{j}=\frac{(1-\phi) J}{\sum_{j=1}^{J} y_{j}} B_{j}, \\
& \pi_{j}=p y_{j}-w_{j} n_{j}=p y_{j}-(1-\phi) p B_{j} n_{j}=\phi p y_{j}, \\
& w_{j} n_{j} / \pi_{j}=1 / \phi-1, \quad \sum_{j=1}^{J} w_{j} n_{j}=(1-\phi) J, \quad \sum_{j=1}^{J} \pi_{j}=\phi J .
\end{aligned}
$$


Results (5) show that labor input in production, $n_{j}$, can be constant, provided that the wage $w_{j}$ and the profit $\pi_{j}$ change in the same proportion. Without this property, there could not be a steady state in the model.

\subsection{Research and development (R\&D)}

Technological change for firm $j$ is characterized by a Poisson process $q_{j}$ as follows. During a short time interval $d \theta$, there is an innovation $d q_{j}=1$ with probability $\Lambda_{j} d \theta$, and no innovation $d q_{j}=0$ with probability $1-\Lambda_{j} d \theta$, where $\Lambda_{j}$ is the arrival rate of innovations in the research process. The arrival rate $\Lambda_{j}$ is an increasing function of labor devoted to $\mathrm{R} \& \mathrm{D}, l_{j}$,

$$
\Lambda_{j}=\lambda l_{j}^{1-\nu}, \quad \lambda>0, \quad \nu \in(0,1),
$$

where $\lambda$ and $\nu$ are constants. Decreasing returns to scale $\nu \in(0,1)$ in $\mathrm{R} \& \mathrm{D}$ are assumed to ensure the existence of equilibrium. Following Horii and Iwaisako (2007), this can be justified by the possibility of duplication: when two workers innovate in the same industry, they produce very likely less than a double amount of innovations.

I denote the serial number of technology in industry $j$ by $t_{j}$ and variables depending on technology $t_{j}$ by superscript $t_{j}$. The invention of a new technology raises $t_{j}$ by one and the level of productivity $B_{j}^{t_{j}}$ by $a>1$. Hence,

$$
B_{j}^{t_{j}}=B_{j}^{0} a^{t_{j}} .
$$

During a short time interval $d \theta$, there is a change in technology from $t_{j}$ to $t_{j}+1$ with probability $\Lambda_{j} d \theta$, and no change with probability $1-\Lambda_{j} d \theta$, where $\Lambda_{j}$ is (5).

The average growth rate of the level of productivity (6) in the stationary state is in fixed proportion $(\lambda \log a)$ to $l_{j}^{1-\nu}$ [cf. Aghion and Howitt (1998), p. 59] and thereby an increasing function of $l_{j}$. Thus, research input $l_{j}$ can be used as a proxy of the growth rate in industry $j$.

Firm $j$ 's dividends are given by

$$
\Pi_{j}=\pi_{j}-w_{j} l_{j},
$$

where $\pi_{j}$ is profit, $w_{j}$ the wage in industry $j, l_{j}$ labor devoted to R\&D and $w_{j} l_{j}$ expenditures on R\&D. Firm $j$ maximizes the present value of its dividends 
(7) by its investment in $\mathrm{R} \& \mathrm{D}, l_{j}$, subject to technological change, given the wage $w_{j}$. The value of firm $j$ at time $T$ is

$$
\Omega\left(t_{j}, w_{j}, \pi_{j}\right)=\max _{l_{j} \text { s.t. }(5),(7)} E \int_{T}^{\infty} \Pi_{j} e^{-r(\theta-T)} d \theta
$$

where $\theta$ is time, $E$ the expectation operator and $r$ the interest rate. In Appendix A, I show that this optimization leads to the two results:

(i) The ratio of dividends to profits, $\Pi_{j} / \pi_{j}$, is a decreasing function of labor devoted to $\mathrm{R} \& \mathrm{D}, l_{j}$ as follows:

$$
\begin{aligned}
\frac{\Pi_{j}}{\pi_{j}}=c_{j} & =c\left(l_{j}\right) \doteq \frac{r+(1-a) \lambda l_{j}^{1-\nu}}{r+(1-a) \nu \lambda l_{j}^{1-\nu}}, \quad r+(1-a) \lambda l_{j}^{1-\nu}>0, \\
c^{\prime} \doteq \frac{d c_{j}}{d l_{j}} & =\frac{(\nu-1) r\left(1-c_{j}\right) c_{j} / l_{j}}{r+(1-a) \lambda l_{j}^{1-\nu}}<0 .
\end{aligned}
$$

This is explained by decreasing returns to scale in R\&D.

(ii) The constraint $w_{j} n_{j} / \pi_{j}=1 / \phi-1$ in (5) can be transformed into the form where labor devoted to production, $n_{j}$, is a decreasing function of the firms' share of value added, $\phi$, but total labor input $n_{j}+l_{j}$ is an increasing function of labor devoted to $\mathrm{R} \& \mathrm{D}, l_{j}$ :

$$
\begin{aligned}
& n_{j}=n\left(l_{j}, \phi\right) \doteq \frac{1 / \phi-1}{1-c\left(l_{j}\right)} l_{j}, \quad \frac{\partial n}{\partial \phi}<0, \quad n_{j}+l_{j}=\frac{1 / \phi-c}{1-c} l_{j}, \\
& \frac{\partial\left(n_{j}+l_{j}\right)}{\partial l_{j}}=\left[\frac{1}{\phi}-c\left(l_{j}\right)\right] \nu \frac{c\left(l_{j}\right)}{1-c\left(l_{j}\right)}-\frac{c^{\prime}\left(l_{j}\right) l_{j}}{1-c\left(l_{j}\right)}>0 .
\end{aligned}
$$

\section{$4 \quad$ Wage bargaining}

Because each industry $j$ possesses a fixed amount $L$ of labor, its full-employment constraint is given by

$$
l_{j}+n_{j} \leq L
$$

where $n_{j}$ and $l_{j}$ are labor inputs in production and $\mathrm{R} \& \mathrm{D}$.

In each industry $j$, the workers' wage $w_{j}$ is determined by bargaining between a union representing workers in industry $j$ (hereafter union $j$ ) and a federation representing the employers of these workers (hereafter employer $j$ ). On the assumption that both parties of bargaining are risk neutral, the problem can be solved as an alternating-offers game. I also assume that the workers have access to perfect unemployment insurance. This ensures that 
all workers in the same industry behave as if there were only one worker in that industry. ${ }^{3}$ I assume, furthermore, that in the case of a dispute there is no production, and consequently neither labor income nor profits. The reference income is then zero for both the union and the employer.

In wage bargaining, at each time $T$, labor union $j$ maximizes the expected present value of wages,

$$
U\left(l_{j}, \phi\right) \doteq E \int_{T}^{\infty}\left(n_{j}+l_{j}\right) w_{j} e^{-r(\theta-T)} d \theta,
$$

and federation $j$ maximizes the expected present value of dividends $\Pi_{j}=$ $c\left(l_{j}\right) \pi_{j}$,

$$
F\left(l_{j}, \phi\right)=E \int_{T}^{\infty} c\left(l_{j}\right) \pi_{j} e^{-r(\theta-T)} d \theta,
$$

subject to the full-employment constraint (9) and the firms' behavior as a producer and an investor. The outcome of this bargaining can be obtained through maximizing the Generalized Nash Product $U_{j}^{\alpha} F_{j}^{1-\alpha}$ by the wage $w_{j}$, where $\alpha \in[0,1]$ is relative union bargaining power. Because $\alpha$ depends on labor market regulation [cf. Binmore et al. (1986)], I assume that the central planner uses $\alpha$ as the policy instrument. In Appendix B, the maximization of the Generalized Nash Product $U_{j}^{\alpha} F_{j}^{1-\alpha}$ yields the following equilibrium condition. If there is any unemployment, both the relative union bargaining power $\alpha$ and the firms' share of valued added, $\phi$, promote R\&D and growth:

$$
\begin{aligned}
& l_{j}=\ell(\alpha, \phi) \text { for } l_{j}+n_{j}<L, \quad \frac{\partial \ell}{\partial \alpha}>0, \quad \frac{\partial \ell}{\partial \phi}>0, \\
& \lim _{\alpha \rightarrow 0}\left(L-l_{j}-n_{j}\right)=0 .
\end{aligned}
$$

\section{The economy}

I consider a symmetric equilibrium with $B_{j}^{0}=B^{0}$, in which case $n_{j}=n$, $l_{j}=l, w_{j}=w$ and $\pi_{j}=\pi$ holds true, In that equilibrium, noting (9) and (12), the full-employment constraint (9) and the constraint $\alpha \leq 1$ can be written as:

$$
L \geq l+n(l, \phi), \quad \ell(1, \phi) \geq \ell(\alpha, \phi)=l .
$$

\footnotetext{
${ }^{3}$ Otherwise, workers' income distribution would affect the unions' behavior and the general equilibrium of the industry. Because this would excessively complicate the analysis, I ignore all distributional aspects in this study and leave them for future investigation.
} 
From (5) and (9) it follows that

$$
\begin{aligned}
& w n=\frac{1}{J} \sum_{j=1}^{J} w_{j} n_{j}=1-\phi, \quad \pi=\frac{1}{J} \sum_{j=1}^{J} \pi_{j}=\phi, \\
& (n+l) w=(1+l / n) w n=(1-c \phi) w n /(1-\phi)=1-c(l) \phi .
\end{aligned}
$$

By (1), (3), (9) and (9), I define the present value of the expected flow of real income per industry, $y$, as [cf. Aghion and Howitt (1998), p. 61]

$$
\begin{aligned}
& \Psi(l, \phi) \doteq E \int_{T}^{\infty} \frac{1}{p} e^{-r(\theta-T)} d \theta=E \int_{T}^{\infty} y e^{-r(\theta-T)} d \theta \\
& =E \int_{T}^{\infty} B n e^{-r(\theta-T)} d \theta=\frac{B(T) n}{r+(1-a) \lambda l^{1-\nu}} \\
& =\left(\frac{1}{\phi}-1\right) \psi(l), \quad \psi(l) \doteq \frac{B(T) l /[1-c(l)]}{r+(1-a) \lambda l^{1-\nu}}, \\
& \frac{\psi^{\prime}}{\psi}=\frac{d \log \psi}{d l}=\frac{1}{l}+\frac{c^{\prime}}{1-c}-\frac{(1-)(1-a) \lambda l^{-\nu}}{r+(1-a) \lambda l^{1-\nu}}>\frac{1}{l}+\frac{(\nu-1) r / l}{r+(1-a) \lambda l^{1-\nu}}-\frac{(1-\nu)(1-a) \lambda l^{-\nu}}{r+(1-a) \lambda l^{1-\nu}} \\
& \quad=1 / l+(\nu-1) / l=\nu / l>0, \\
& \partial \Psi / \partial l=(1 / \phi-1) \psi^{\prime}>0 .
\end{aligned}
$$

Holding the firms' share of value added, $\phi$, constant, a higher level of R\&D (i.e. a bigger $l$ ) increases the present value of the expected flow of real income, $\Psi$.

The unions and the firms lobby the central planner which decides on the firms' market power $\varphi$ and the unions's relative bargaining power $\alpha$. Following Grossman and Helpman (1994a), I assume that the central planner has its own interests and collects contributions $R_{u}$ and $R_{f}$ from the union and employer lobbies. A member of the worker lobby earns wages $(n+l) w$ minus political contributions $R_{u}$. A member of the employer lobby earn dividends $\Pi$ minus political contributions $R_{u}$. Because the effects through the the price level $p$ can be internalized at the level of the economy, the worker lobby maximizes the present value $\mathcal{U}$ of the expected flow of a typical worker's real income $\left[(n+l) w-R_{u}\right] / p$, and the employer lobby maximizes the present value $\mathcal{F}$ of the expected flow of a typical firm's real dividends $\left(\Pi-R_{f}\right) / p$ at time $T$. Noting (9), (12), (13) and (13), these targets can be defined as:

$$
\begin{aligned}
& \mathcal{U}\left(\ell(\alpha, \phi), \phi, R_{u}\right)=\mathcal{U}\left(l, \phi, R_{u}\right) \doteq E \int_{T}^{\infty} \frac{(n+l) w-R_{u}}{p} e^{-r(\theta-T)} d \theta \\
= & \Psi\left[(n+l) w-R_{u}\right]=\Psi(l, \phi)\left[1-c(l) \phi-R_{u}\right], \\
& \mathcal{F}\left(\ell(\alpha, \phi), \phi, R_{u}\right)=\mathcal{F}\left(l, \phi, R_{f}\right) \doteq E \int_{T}^{\infty} \frac{\Pi-R_{f}}{p} e^{-r(\theta-T)} d \theta \\
& =\Psi\left[\Pi-R_{f}\right]=\Psi\left[c(l) \pi-R_{f}\right]=\Psi(l, \phi)\left[c(l) \phi-R_{f}\right],
\end{aligned}
$$


where

$$
\mathcal{U}\left(l, \phi, R_{f}\right)+\mathcal{F}\left(l, \phi, R_{f}\right)=\left(1-R_{u}-R_{f}\right) \Psi(l, \phi) .
$$

Noting (13), the present value the expected flow of the real political contributions at time $T$ is given by

$$
E \int_{T}^{\infty} \frac{R_{u}+R_{f}}{p} e^{-r(\theta-T)} d \theta=\Psi(l, \phi)\left(R_{u}+R_{f}\right) .
$$

Given this and (13), I specify the central planner's utility function as follows:

$$
\begin{aligned}
& G\left(\ell(\alpha, \phi), \phi, R_{u}, R_{f}\right)=G\left(l, \phi, R_{u}, R_{f}\right) \\
& \quad \doteq E \int_{T}^{\infty} \frac{R_{u}+R_{f}}{p} e^{-r(\theta-T)} d \theta+\zeta_{w} \mathcal{U}\left(l, \phi, R_{u}\right)+\zeta_{f} \mathcal{F}\left(l, \phi, R_{f}\right) \\
& \quad=\Psi(l, \phi)+\left(\zeta_{w}-1\right) \mathcal{U}\left(l, \phi, R_{u}\right)+\left(\zeta_{f}-1\right) \mathcal{F}\left(l, \phi, R_{f}\right),
\end{aligned}
$$

where constants $\zeta_{w} \geq 0$ and $\zeta_{f} \geq 0$ are weights of the worker's and the firm's welfare in the government's preferences, respectively.

The objective function of Grossman and Helpman (1994a), (15), is widely used in models of common agency and it has been justified as follows. The politicians are mainly interested in their own income which consists of the contributions from the public, $R_{u}+R_{f}$, but because they must defend their position in general elections, they must sometimes take the utilities of the interest groups $\mathcal{U}\left(l, \phi, R_{u}\right)$ and $\mathcal{F}\left(l, \phi, R_{f}\right)$ into account directly. The linearity of (15) in $\Psi\left[R_{u}+R_{f}\right]$ is assumed, for simplicity.

\section{The political equilibrium}

I assume for a while that the central planner can smoothly regulate unions' and firms' market power $(\alpha, \varphi)$. The results can then be extended for the case where the central planner's choices are more discrete.

Because the function $\ell(\alpha, \phi)$ establishes one-to-one correspondence from the central planner's instrument $\alpha$ to $l$, one can in the model consider labor devoted to R\&D (= the measure of the growth rate, cf. subsection 3.2) $l$ as a policy variable. The unions' and employers' lobbies try to affect the central planner by their contributions $R_{u}$ and $R_{f}$. The contribution schedules are therefore functions of the central planner's policy variables:

$$
R_{u}(l, \phi), \quad R_{f}(l, \phi)
$$


The central planner maximizes its utility function $(15)$ by $(l, \phi)$, given the contribution schedules (15) and the constraints (5) and (12). Following proposition 1 of Dixit at al. (1997), a subgame perfect Nash equilibrium for this game is a set of contribution schedules $R_{u}(l, \phi)$ and $R_{f}(l, \phi)$ and policy $(l, \phi)$ such that the following conditions $(i)-(i v)$ hold:

(i) Contributions $R_{u}$ and $R_{f}$ are non-negative but no more than the contributor's income.

(ii) The policy $(\phi, l)$ maximizes the central planner's welfare (15) taking the contribution schedules $R_{u}$ and $R_{f}$ as given,

$$
(l, \phi) \in \arg \max _{\substack{(l, \phi) \\(5) \text { s.t. } \text { and }(12)}} G\left(l, \phi, R_{u}(l, \phi), R_{f}(l, \phi)\right) ;
$$

(iii) The worker lobby (employer lobby) cannot have a feasible strategy $R_{u}(l, \phi)\left(R_{f}(l, \phi)\right)$ that yields it a higher level of utility than in equilibrium, given the central planner's anticipated decision rule,

$$
\begin{aligned}
& (l, \phi)=\arg \max _{(l, \phi)} \text { s.t. (5) and (12) } \mathcal{U}\left(l, \phi, R_{u}(l, \phi)\right) \text {, } \\
& (l, \phi)=\arg \max _{(l, \phi)} \text { s.t. (5) and (12) } \mathcal{F}\left(l, \phi, R_{f}(l, \phi)\right) \text {. }
\end{aligned}
$$

(iv) The worker lobby (employer lobby) provides the central planner at least with the level of utility than in the case it offers nothing $R_{u}=0$ $\left(R_{f}=0\right)$, and the central planner responds optimally given the other lobby's contribution function,

$$
\begin{aligned}
& G\left(l, \phi, R_{u}(l, \phi), R_{f}(l, \phi)\right) \\
& \geq \max _{(l, \phi)} \text { s.t. }(5) \text { and }(12) G\left(l, \phi, R_{u}(l, \phi), 0\right), \\
& G\left(l, \phi, R_{u}(l, \phi), R_{f}(l, \phi)\right) \\
& \geq \max _{(l, \phi)} \text { s.t. (5) and (12) } G\left(l, \phi, 0, R_{f}(l, \phi)\right) .
\end{aligned}
$$

Noting (15) and (16), the central planner's utility function (15) changes into

$$
\begin{aligned}
& \mathcal{G}(l, \phi) \doteq G\left(l, \phi, R_{u}(l, \phi), R_{f}(l, \phi)\right) \\
& =\Psi(l, \phi)+\left(\zeta_{w}-1\right) \max _{(l, \phi)} \text { s.t. }(5) \text { and }(12) \mathcal{U}\left(l, \phi, R_{u}(l, \phi)\right) \\
& \quad+\left(\zeta_{f}-1\right) \max _{(l, \phi)} \text { s.t. }(5) \text { and }(12) \\
& \mathcal{F}\left(l, \phi, R_{f}(l, \phi)\right) \\
& \partial \mathcal{G} / \partial l=\partial \Psi / \partial l, \quad \partial \mathcal{G} / \partial \phi=\partial \Psi / \partial \phi .
\end{aligned}
$$

The Lagrangean for the maximization of the central planner's utility function $(16)$ by $(l, \phi)$ subject to the constraints $(5)$ and (12) is given by

$$
\mathcal{H}=\mathcal{G}(l, \phi)+\varepsilon[L-l-n(l, \phi)]+\vartheta[\ell(1, \phi)-l],
$$


where the multipliers $\varepsilon$ and $\vartheta$ satisfy the conditions

$$
\begin{aligned}
& \varepsilon[L-l-n(l, \phi)]=0, \quad \varepsilon \geq 0, \\
& \vartheta[\ell(1, \phi)-l]=0, \quad \vartheta \geq 0 .
\end{aligned}
$$

Noting (9), (12), (13), (16) and (16), the first-order conditions for the maximization of the central planner's utility are the following:

$$
\begin{aligned}
\partial \mathcal{H} / \partial \phi & =\partial \mathcal{G} / \partial \phi-\varepsilon \partial n / \partial \phi+\vartheta \partial \ell / \partial \phi \\
= & \partial \Psi / \partial \phi-\varepsilon \partial n / \partial \phi+\vartheta \partial \ell(1, \phi) / \partial \phi=0, \\
\partial \mathcal{H} / \partial l & =\partial \mathcal{G} / \partial l-\varepsilon[1+\partial n / \partial l]-\vartheta \\
& =\partial \Psi / \partial l-\varepsilon[1+\partial n / \partial l]-\vartheta=0 .
\end{aligned}
$$

There are two possibilities in labor market regulation:

(a) If the labor market is deregulated, $\alpha \rightarrow 0$, then, by (12), there is full employment $L=l+n(l, \phi)$. In that case, there cannot be monopoly unions $\alpha=1$ that can dictate wages and, by (12), (17) and (18), $\ell(1, \phi)>l, \vartheta=0, \varepsilon=\frac{\partial \Psi}{\partial l} /\left(1+\frac{\partial n}{\partial l}\right)>0$ hold true.

(b) Otherwise, when $\alpha$ is sufficiently large, the labor market is regulated, there is unemployment $L>l+n(l, \phi)$ and, by (12), (17) and (18), $\varepsilon=0, \vartheta=\frac{\partial \Psi}{\partial l}>0, \ell(1, \phi)=l$ and $\alpha=1$ hold true.

The central planner can increase its welfare either (a) by increasing the level of income or (b) by speeding up growth. If (a) is more effective than (b), then it eliminates union power altogether to have full employment. On the other hand, if (b) is more effective than (a), then it supports labor unions to promote cost-escaping $R \& D$.

\section{Appendix}

A. The functions (9) and (9)

From (5) and (6) it follows that

$$
\pi_{j}^{t_{j}+1} / \pi_{j}^{t_{j}}=B_{j}^{t_{j}+1} / B_{j}^{t_{j}}=a .
$$

The Bellman equation corresponding to (8) is given by [cf. Dixit and Pindyck (1994), Wälde (2007)]

$$
r \Omega\left(t_{j}, w_{j}\right)=\max _{l_{j}}\left\{\pi_{j}-w_{j} l_{j}+\lambda l_{j}^{1-\nu}\left[\Omega\left(t_{j}+1, w_{j}, \pi_{j}\right)-\Omega\left(t_{j}, w_{j}, \pi_{j}\right)\right]\right\} .
$$


The first-order condition corresponding to this is given by

$$
(1-\nu) \lambda l_{j}^{-\nu}\left[\Omega\left(t_{j}+1, w_{j}, \pi_{j}\right)-\Omega\left(t_{j}, w_{j}, \pi_{j}\right)\right]=w_{j} .
$$

I try the solution

$$
\Pi_{j}=c_{j} \pi_{j}, \quad c_{j} \in(0,1), \quad \Omega=\Pi_{j} / \delta_{j},
$$

in which dividends $\Pi_{j}$ is in fixed proportion $c_{j}$ to profits $\pi_{j}$, and the subjective discount factor $\delta_{j}>0$ is independent of income $\pi_{j}$. Given (20) and (23), one obtains

$$
\widetilde{\Omega} \doteq \Omega\left(t_{j}+1, w_{j}, \pi_{j}\right)=c_{j} \pi_{j}^{t_{j}+1} / \delta_{j}=a c_{j} \pi_{j}^{t_{j}} / \delta_{j}=a \Omega\left(t_{j}, w_{j}, \pi_{j}\right) .
$$

Inserting this and (23) into (21), one obtains

$$
r=\Pi_{j} / \Omega+\lambda l_{j}^{1-\nu}(\widetilde{\Omega} / \Omega-1)=\delta_{j}+(a-1) \lambda l_{j}^{1-\nu}
$$

and

$$
\delta_{j}=r+(1-a) \lambda l_{j}^{1-\nu}>0 .
$$

From (23) and (7) it follows that

$$
w_{j} l_{j}=\pi_{j}-\Pi_{j}=\left(1 / c_{j}-1\right) \Pi_{j}=\left(1-c_{j}\right) \pi_{j} .
$$

Inserting (23), (24), (25) and (26) into (22), one obtains

$$
\begin{aligned}
& (a-1)(1-\nu) \lambda=(1-\nu) \lambda\left(\frac{\widetilde{\Omega}}{\Omega}-1\right)=\frac{w_{j}}{\Omega} l_{j}^{\nu} \\
& =\frac{w_{j} \delta_{j}}{\Pi_{j}} l_{j}^{\nu}=\frac{\delta_{j}}{l_{j}}\left(\frac{1}{c_{j}}-1\right) l_{j}^{\nu}=\left(\frac{1}{c_{j}}-1\right) \delta_{j} l_{j}^{\nu-1} \\
& =\left[r l_{j}^{\nu-1}+(1-a) \lambda\right] \frac{1-c_{j}}{c_{j}} .
\end{aligned}
$$

Differentiating the logarithm of this equation totally yields

$$
\frac{(\nu-1) r l_{j}^{\nu-2} d l_{j}}{r l_{j}^{\nu-1}+(1-a) \lambda}=\left(\frac{1}{1-c_{j}}+\frac{1}{c_{j}}\right) d c_{j}=\frac{d c_{j}}{\left(1-c_{j}\right) c_{j}} .
$$

Noting (5), (23), (25), this equation defines the function

$$
\begin{aligned}
& \frac{\Pi_{j}}{\pi_{j}}=c_{j}=c\left(l_{j}\right)=\frac{r+(1-a) \lambda l_{j}^{1-\nu}}{r+(1-a) \lambda \nu l_{j}^{1-\nu}}>0, \quad 1-c_{j}=\frac{(1-\nu)(a-1) \lambda l_{j}^{1-\nu}}{r+(1-a) \lambda \nu l_{j}^{1-\nu}}, \\
& c^{\prime} \doteq \frac{d c_{j}}{d l_{j}}=\frac{(\nu-1) r l_{j}^{\nu-2}\left(1-c_{j}\right) c_{j}}{r l_{j}^{\nu-1}+(1-a) \lambda}=\frac{\overbrace{\nu-1}^{\nu-r} \overbrace{\left(1-c_{j}\right) c_{j} / l_{j}}}{\underbrace{r+(1-a) \lambda l_{j}^{1-\nu}}_{+}}<0 .
\end{aligned}
$$


From (27) it follows that

$$
\begin{aligned}
& \frac{d}{d l_{j}}\left[\frac{l_{j}}{1-c\left(l_{j}\right)}\right]=\frac{1}{1-c_{j}}+\frac{l_{j} c^{\prime}}{\left(1-c_{j}\right)^{2}}=\frac{1}{1-c_{j}}+\frac{(\nu-1) r c_{j} /\left(1-c_{j}\right)}{r+(1-a) \lambda l_{j}^{1-\nu}} \\
& =\frac{1}{1-c_{j}}\left[1+\frac{(\nu-1) r c_{j}}{r+(1-a) \lambda l_{j}^{1-\nu}}\right]=\frac{1}{1-c_{j}}\left[1+\frac{(\nu-1) r}{r+(1-a) \lambda \nu l_{j}^{1-\nu}}\right] \\
& =\frac{\nu}{1-c_{j}} \frac{r+(1-a) \lambda l_{j}^{1-\nu}}{r+(1-a) \lambda \nu l_{j}^{1-\nu}}=\frac{\nu c_{j}}{1-c_{j}}>0 .
\end{aligned}
$$

Finally, noting (5), (26), (27) and (27), one obtains

$$
\begin{aligned}
& n_{j}=\left(\frac{1}{\phi}-1\right) \frac{\pi_{j}}{w_{j}}=\frac{(1 / \phi-1) l_{j}}{1-c_{j}}=\frac{(1 / \phi-1) l_{j}}{1-c\left(l_{j}\right)} \doteq n\left(l_{j}, \phi\right), \\
& n_{j}+l_{j}=\frac{1 / \phi-c_{j}}{1-c_{j}} l_{j}, \\
& \frac{\partial\left(n_{j}+l_{j}\right)}{\partial l_{j}}=\left(\frac{1}{\phi}-c_{j}\right) \frac{d}{d l_{j}}\left[\frac{l_{j}}{1-c\left(l_{j}\right)}\right]-\frac{c^{\prime} l_{j}}{1-c_{j}} \\
& =[\underbrace{\frac{1}{\phi}-c\left(l_{j}\right)}_{+}] \nu \frac{c\left(l_{j}\right)}{1-c\left(l_{j}\right)}-\underbrace{c^{\prime}\left(l_{j}\right)}_{-} \underbrace{\frac{l_{j}}{1-c\left(l_{j}\right)}}_{+}>0 .
\end{aligned}
$$

Results (27)-(27) imply and (9) and (9).

\section{B. The function (12)}

Because there is one-to-one correspondence between the wage $w_{j}$ and labor input in R\&D, $l_{j}$, through (5) and (9), in the maximization of the Generalized Nash Product $\mathcal{U}_{j}^{\alpha} F_{j}^{1-\alpha}$ can be maximized by $l_{j}$. Noting (5), I obtain that both $\left(n_{j}+l_{j}\right) w_{j}$ and $\Pi_{j}=c_{j} \pi_{j}$ grow at the same rate as $B_{j}$. The parties' expected utilities (10) and (11) can then be transformed into the following form [Aghion and Howitt (1998), p. 61]

$$
U\left(l_{j}, \phi\right)=\frac{B_{j}(T)\left(n_{j}+l_{j}\right) w_{j}}{B_{j}\left[r+(1-a) \lambda l_{j}^{1-\nu}\right]}, \quad F\left(l_{j}, \phi\right)=\frac{B_{j}(T) c\left(l_{j}\right) \pi_{j}}{B_{j}\left[r+(1-a) \lambda l_{j}^{1-\nu}\right]} .
$$

Given (5), (9), (9) and (27), the outcome of bargaining is obtained through maximizing by $l_{j}$ the following increasing transformation of $U_{j}^{\alpha} \mathcal{F}_{j}^{1-\alpha}$ :

$$
\begin{aligned}
& \Gamma_{j}\left(l_{j}, C, \alpha\right) \doteq \log \left[U_{j}^{\alpha} F_{j}^{1-\alpha}\right] \alpha \log U_{j}+(1-\alpha) \log F_{j} \\
& =\alpha \log \left[\left(n_{j}+l_{j}\right) w_{j} B_{j}^{-1}\right]+(1-\alpha) \log \left[c\left(l_{j}\right) \pi_{j} B_{j}^{-1}\right] \\
& \quad \quad-\log \left[r+(1-a) \lambda l_{j}^{1-\nu}\right]+\Delta \\
& =\alpha \log \left(1+l_{j} / n_{j}\right)+\log \left[w_{j} n_{j} B_{j}^{-1}\right] \\
& +(1-\alpha) \log c\left(l_{j}\right)-\log \left[r+(1-a) \lambda l_{j}^{1-\nu}\right]+\Delta \\
& =\alpha \log \left(1+l_{j} / n_{j}\right)+\log n_{j}+(1-\alpha) \log c\left(l_{j}\right) \\
& -\log \left[r+(1-a) \lambda l_{j}^{1-\nu}\right]+\Delta \\
& =\alpha \log \left[1 / \phi-c\left(l_{j}\right)\right]+\log l_{j}-\log \left[1-c\left(l_{j}\right)\right] \\
& +(1-\alpha) \log c\left(l_{j}\right)-\log \left[r+(1-a) \lambda l_{j}^{1-\nu}\right]+\Delta \\
& \text { with } \quad r+(1-a) \lambda l_{j}^{1-\nu}>0,
\end{aligned}
$$


where $\Delta$ denotes terms that are independent of $l_{j}$, subject to the constraint $l_{j}+n\left(l_{j}, \phi\right) \leq L$. The Lagrangean of this problem is given by

$$
\mathcal{L}_{j}=\Gamma_{j}\left(l_{j}, C, \alpha\right)+\beta\left[L-l_{j}-n\left(l_{j}, \phi\right)\right],
$$

where the multiplier $\beta$ satisfies the conditions

$$
\beta\left[L-l_{j}-n\left(l_{j}, \phi\right)\right]=0, \quad \beta \geq 0 .
$$

Noting (28), (28) and (29), the first-order condition is

$$
\partial \mathcal{L}_{j} / \partial l_{j}=\partial \Gamma_{j} / \partial l_{j}-\beta\left[1+\partial n / \partial l_{j}\right]=0,
$$

where

$$
\begin{aligned}
& \frac{\partial \Gamma_{j}}{\partial l_{j}}=\frac{1}{l_{j}}+\frac{c^{\prime}\left(l_{j}\right)}{1-c\left(l_{j}\right)}+(1-\alpha) \frac{c^{\prime}\left(l_{j}\right)}{c\left(l_{j}\right)}-\frac{\alpha c^{\prime}\left(l_{j}\right)}{1 / \phi-c\left(l_{j}\right)} \\
& +\frac{(1-\nu)(a-1) \lambda l_{j}^{-\nu}}{r+(1-a) \lambda l_{j} l_{j}^{1-\nu}} .
\end{aligned}
$$

which defines the function

$$
l_{j}=\ell(\alpha, \phi) \text { for } l_{j}+n_{j}<L .
$$

Noting

$$
\frac{\partial^{2} \Gamma_{j}}{\partial l_{j} \partial \alpha}=-\frac{c^{\prime}}{c}-\frac{c^{\prime}}{1 / \phi-c}>0, \quad \frac{\partial^{2} \Gamma_{j}}{\partial l_{j} \partial \phi}=-\frac{\alpha c^{\prime}}{(1-\phi c)^{2}}>0,
$$

and the second-order condition $\partial^{2} \Gamma_{j} / \partial l_{j}^{2}<0$ for $l_{j}+n_{j}<L$, one obtains

$$
\begin{aligned}
& \frac{\partial \ell}{\partial \alpha}=-\frac{\partial^{2} \Gamma_{j}}{\partial l_{j} \partial \alpha} / \frac{\partial^{2} \Gamma_{j}}{\partial l_{j}^{2}}>0 \text { and } \\
& \frac{\partial \ell}{\partial \phi}=-\frac{\partial^{2} \Gamma_{j}}{\partial l_{j} \partial \phi} / \frac{\partial^{2} \Gamma_{j}}{\partial l_{j}^{2}}>0 \text { for } l_{j}+n_{j}<L .
\end{aligned}
$$

From (9), (28), (29), (30) and (31) it follows that

$$
\begin{aligned}
& \lim _{\alpha \rightarrow 0} \frac{\partial \Gamma_{j}}{\partial l_{j}}=\frac{1}{l_{j}}+\frac{c^{\prime}}{1-c}+\frac{c^{\prime}}{c}+\frac{(1-\nu)(a-1) \lambda l_{j}^{-\nu}}{r+(1-a) \lambda l_{j}^{1-\nu}} \\
& =\frac{1}{l_{j}}+\frac{c^{\prime} / c}{1-c}+\frac{(1-\nu)(a-1) \lambda l_{j}^{-\nu}}{r+(1-a) \lambda l_{j}^{1-\nu}}=\frac{c^{\prime} / c}{1-c}+\frac{1}{l_{j}} \frac{r+(1-a) \nu \lambda l_{j}^{1-\nu}}{r+(1-a) \lambda l_{j}^{1-\nu}} \\
& =\frac{(\nu-1) r / l_{j}}{r+(1-a) \lambda l_{j}^{1-\nu}}+\frac{1}{l_{j}} \frac{r+(1-a) \nu \lambda l_{j}^{1-\nu}}{r+(1-a) \lambda l_{j}^{1-\nu}}=\frac{\nu}{l_{j}} \frac{r+(1-a) \lambda l_{j}^{-\nu}}{r+(1-a) \lambda l_{j}^{1-\nu}}=\frac{\nu}{l_{j}}>0, \\
& \left(\lim _{\alpha \rightarrow 0} \beta\right) \lim _{\alpha \rightarrow 0}(\underbrace{1+\frac{\partial n}{\partial l_{j}}}_{+})=\lim _{\alpha \rightarrow 0} \frac{\partial \Gamma_{j}}{\partial l_{j}}>0, \\
& \lim _{\alpha \rightarrow 0} \beta>0, \quad \lim _{\alpha \rightarrow 0}\left(L-l_{j}-n_{j}\right)=0 .
\end{aligned}
$$

Results (32), (33) and (34) imply (12). 


\section{Conclusions}

This paper examines an economy with a large number of industries, each producing a different good. Technological change follows a Poisson process where firms improve their productivity through investment in R\&D. The less there are firms in the economy or the more they can coordinate their actions, the higher their profits. Labor is used in production or R\&D. All workers are unionized and their wages depend on relative union bargaining power. If this power is high enough, then there is involuntary unemployment. Both workers and firms lobby the central planner of the economy which affects firms' and unions' market power. The main findings of the paper can be summarized the follows. Unions' and firms' market power decreases the level of income at each moment of time. On the other hand, the greater the firm's share of value added or the higher union wages, more incentives the firm has to increase the productivity of labor through $R \& D$. In this respect, there can be an optimal amount of unions' and firms' market power. Concerning the regulation of relative union bargaining power, the central planner can increase its welfare either (a) by increasing the level of income or (b) by speeding up economic growth. If (a) is more effective than (b), then the central planner eliminates union power altogether to have full employment. On the other hand, if (b) is more effective than (a), then the central planner supports labor unions to promote cost-escaping R\&D. 


\section{References:}

P. Aghion, and P. Howitt. Endogenous Growth Theory. The MIT Press, Cambridge (Mass.), 1998.

D. Bernheim, and M.D. Whinston. Menu auctions, resource allocation, and economic influence. Quarterly Journal of Economics, 101:1-31, 1986.

K. Binmore, K., A. Rubinstein, and A. Wolinsky. The Nash Bargaining Solution in Economic Modelling. Rand Journal of Economics, 17:176-188, 1986.

A. Dixit. Comparative statics for oligopoly. International Economic Review, 27:107-122, 1986.

A. Dixit, G.M. Grossman, and E. Helpman. Common agency and coordination: general theory and application to management policy making. Journal of Political Economy, 105:752-769, 1997.

A. Dixit, and K. Pindyck. Investment under Uncertainty. Princeton University Press, Princeton, 1994.

G.M. Grossman, and E. Helpman. Protection for sale. American Economic Review, 84:833-850, 1994a.

G.M. Grossman, and E. Helpman. Innovation and Growth. The MIT Press, Cambridge (Mass.), 1994b.

R. Horii, and T. Iwaisako. Economic growth with imperfect protection of intellectual property rights. Journal of Economics, 90:45-85, 2007.

K. Wälde. A Model of Creative Destruction with Undiversifiable Risk and Optimizing Households. The Economic Journal, 109:C156-C171, 1999. 